\title{
PROTOTIPE ALAT PENDETEKSI KEBOCORAN GAS BERACUN CO PADA MOBIL MENGGUNAKAN ARRAY SENSOR BERBASIS SMS GATEWAY
}

\author{
Slamet Widodo ${ }^{1}$,Dendy Andrian ${ }^{2}$ \\ ${ }^{1}$ Jurusan Teknik Komputer, Politeknik Negeri Sriwijaya Palembang Jalan Srijaya Negara, Palembang 30139 \\ Telp. 0711 - 353414 Fax. 0711 - 355918 website : http://polsri.ac.id \\ ${ }^{1}$ slamet_widodo2003@yahoo.com
}

Abstrak: Perkembangan teknologi otomotif sekarang sangat pesat sekali dimana produsen mobil memberikan berbagai fasilitas untuk kebutuhan pemakai agar merasa nyaman ketika berada dalam kendaraan tersebut. Namun tanpa disadari terdapat ancaman bahaya bagi pengguna kendaraan yang berasal dari fasilitas-fasilitas tersebut salah satunya seperti AC (Air Conditioner). Ketika sistem pada AC terjadi kebocoran kecil saja maka gas beracun CO (Karbon monoksida) akan memenuhi ruang pada kendaraan mobil yang tertutup. Hal ini dapat terjadi apabila ada kebocoran pada sistem pembuangan kendaraan yang memicu gas CO masuk kedalam mobil. Gas CO ini merupakan hasil dari pembakaran yang tidak sempurna dari senyawa karbon yang sering terjadi pada mesin pembakaran dalam. Gas CO terbentuk apabila terdapat kekurangan oksigen dalam proses pembakaran. Disinilah alat pendeteksi kebocoran gas beracun CO sangat dibutuhkan untuk mendeteksi gas CO yang berbahaya ini karena gas ini tidak berwarna, tidak berbau, dan tidak berasa sehingga membuatnya sulit untuk dideteksi dengan menggunakan indra manusia sehingga dapat menyebabkan kematian tanpa disadari oleh yang menghirupnya. Adannya fenomena tersebut dibutuhkan perancangan prototipe alat untuk mendeteksi gas CO untuk memberikan rasa aman bagi pengguna mobil. Sebagai pengendali utama pada sistem yaitu mikrokontroller Atmega32 sebagai pengendali kerja alat. Dan Array sensor yaitu TGS 2600 dan 2442 untuk mengetahui kadar kandungan gas karbon monoksida(CO). Ketika sensor TGS 2600 mendeteksi kadar gas CO $>25$ ppm maka itu berarti status sangat berbahaya, sehingga buzzer akan berbunyi , kipas aktif berputar, motor DC aktif menggerakkan power window dan sms gateway akan mengirim pesan bahaya kepada pemilik mobil. Berdasarkan hasil pengujian dan pengukuran pada alat pendeteksi gas CO ,skala yang didapatkan sebagai perbandingan data maksimun tingkat pendeteksian dengan kadar deteksi akhir sensor setelah dilakukan pengukuran pada saat kondisi aman dengan tegangan 0,3 VDC kondisi gas CO sebesar 4 ppm, mendekati bahaya dengan tegangan 1,2 VDC kondisi gas CO sebesar 10 ppm, kondisi bahaya dengan tegangan 3,2 VDC kondisi gas CO sebesar 22 ppm dan kondisi sangat bahaya dengan tegangan 4 VDC dengan kondisi gas CO sebesar 26 ppm.

Kata Kunci: Gas beracun CO, Array sensor, Sms Gateway

\begin{abstract}
The development of automotive technology is now very rapidly once that car manufacturers provide a wide range of facilities to the user's needs in order to feel comfortable when it is in the vehicle. But without realizing there is a danger for users of vehicles originating from these facilities one as AC (Air Conditioner). When the air conditioning system on a small leak the toxic gas $\mathrm{CO}$ (carbon monoxide) will meet on the space vehicles closed car. This can occur if there is a leak in the exhaust system of vehicles
\end{abstract}

that trigger the $\mathrm{CO}$ gas into the car. CO gas is the result of incomplete combustion of carbon compounds that often occur in combustion engines. CO gas is formed when there is a lack of oxygen in the combustion process. This is where the toxic gas leak detectors are needed to detect CO CO dangerous gas because this gas is colorless, odorless, and tasteless thus making it difficult to detect using human senses so as to cause the death unnoticed by the inhale. Adannya the phenomenon takes the design of a 
prototype tool for detecting $\mathrm{CO}$ gas to provide security for car users. As the main controller in the system is microcontroller ATmega32 as a work tool control. And a sensor array that TGS 2600 and 2442 to determine the gas content levels of carbon monoxide (CO). TGS 2600 when the sensor detects $\mathrm{CO}$ gas concentration> $25 \mathrm{ppm}$ then it means that the status is very dangerous, so the buzzer will sound, active fan spins, active DC motors drive the power window and sms gateway will send a message to the dangers of car owners. Based on test results and measurements on $\mathrm{CO}$ gas detection devices, the scale of the data obtained for comparison with the maximum level detection level detection sensor after the end of the current measurement at safe condition with a voltage of $0.3 \mathrm{VDC} C O$ gas conditions at $4 \mathrm{ppm}$, approaching danger with a voltage of $1,2 \mathrm{VDC}$ condition at $10 \mathrm{ppm} C O$ gas, hazardous conditions with a voltage of 3.2 VDC CO gas conditions at $22 \mathrm{ppm}$ and very dangerous conditions with voltage 4 VDC to conditions amounting to $26 \mathrm{ppm}$ of $\mathrm{CO}$ gas.

Keywords: toxic gases $\mathrm{CO}$, sensor arrays, sms gateway

\section{Pendahuluan}

Semakin berkembangnya kendaraan bermotor dengan sangat pesat, khususnya untuk provinsi Sumatera Selatan. Seperti dikutip www.antarasumsel.com, Kepala Dinas Pendapatan Daerah Sumsel Eppy Mirza mengatakan, berdasarkan data yang masuk hinggga Desember 2012 ternyata jumlah kendaraan di provinsi ini lebih kurang 1,6 juta unit baik mobil maupun sepeda motor. Jumlah kendaraan tersebut sudah termasuk mobil dan motor dinas yang dimiliki pemerintah, TNI dan Polri. Dengan jumlah yang banyak tersebut maka banyak juga gas buang yang akan keluar dari sisa pembakaran kendaraan tersebut. Gas buang pada kendaraan adalah sisa dari hasil pembakaran berupa air $\left(\mathrm{H}_{2} \mathrm{O}\right)$, Karbon Monoksida (CO), Karbon Dioksida $\left(\mathrm{CO}_{2}\right)$, Nitrogen Oksida $\left(\mathrm{NO}_{\mathrm{x}}\right)$, Sulfur Dioxide $\left(\mathrm{SO}_{2}\right)$ dan senyawa Hidrat Carbon (HC) sebagai ketidak sempurnaan proses pembakaran serta partikel lepas. Apabila terhirup, gas CO akan ikut peredaran darah dan akan menghalangi masuknya oksigen yang akan dibutuhkan oleh tubuh. Semua itu adalah resiko dengan berkembangnya pola pikir manusia untuk meningkatkan fasilitas pada kendaraan. Kendaraan merupakan suatu sarana transportasi yang sangat penting yang banyak digunakan oleh manusia dalam menjalankan kegiatan. Termasuk salah satu yang populer adalah mobil. Maka dibuatlah beberapa fasilitas seperti halnya AC (Air Conditioner), Power Window, yang dapat memberikan kenyamanan pada pengguna mobil.

Namun dari berbagai keuntungan yang di dapat dari beberapa tekonologi tersebut, bukan berarti teknologi tersebut tanpa error. Khusunya adalah AC (Air Conditioner). Jika pada mesin terjadi pembakaran yang tidak sempurna dan akan menghasilkan gas CO, Gas akan masuk melalui lubang AC (Air Conditioner) apabila terjadi kebocoran pada lubang AC (Air Conditioner). Gas ini sangat berbahaya karena tidak berwarna, tidak berbau, dan tidak berasa. Kondisi ini sangat berbahaya bagi manusia karena dapat menyebabkan kematian.

\section{TINJAUAN PUSTAKA}

Mikrokontroler adalah sebuah sistem microprocesor di mana di dalamnya sudah terdapat CPU, ROM, RAM, I/O, Clock dan Peralatan internal lainnya yang sudah saling terhubung dan terorganisasi dengan baik oleh pabrik pembuatnya dan dikemas dalam satu chip yang siap pakai. Sehingga kita tinggal memprogram isi ROM sesuai aturan penggunaan oleh pabrik yang membuatnya.[1].

\section{Mikrokontroler ATmega32 adalah} mikrokontroler 8-bit keluaran Atmel dari keluarga AVR. Mikrokontroler ini dirancang berdasarkan arsitektur AVR RISC (Reduced Instruction Set 
Jurnal Pseudocode, Volume II Nomor 2, September 2015, ISSN 2355 - 5920

Computer) yang mengeksekusi satu instruksi dalam satu siklus clock sehingga dapat mencapai eksekusi instruksi sebesar 1 MIPS (Million Instruction Per Second) setiap $1 \mathrm{MHZ}$ frekuensi clock yang digunakan mikrokontroler tersebut. Frekuensi clock yang digunakan dapat diatur melalui fuse bits dan kristal yang digunakan. Jika kristal yang digunakan sebesar 16 MHZ sehingga frekuensi clock-nya sebesar 16 MHZ maka eksekusi instruksinya mencapai 16 MIPS.

ATmega32 memiliki fitur utama antara lain: 16K x 16 byte In-System Programmable Flash Program Memory dari alamat $0000 \mathrm{H}$ sampai 3FFFH. Flash memory ini terbagi menjadi dua bagian yaitu application flash section dan boot flash section. Data memori sebesar 2144 byte yang terbagi atas 32 general purpose register, 64 I/O register, dan 2KB internal SRAM (Static Random Access Memory), 1 KB EEPROM (Electrically Eraseable Read Only Memory), 32 I/O pin, tiga unit timer/counter, internal dan eksternal interrupt, USART (Universal Synchronous and Asynchronous Receiver Transceiver), TWI (Twowire Serial Interface), 10-bit ADC (Analog to Digital Converter) delapan saluran, SPI (Serial Programmable Interface), watchdog timer, dan internal clock generator. Seperti telah disebutkan di atas ATmega32 memiliki 32 general purpose register, dan register ini terhubung langsung dengan dengan ALU (Arithmatic Logic Unit) sehingga dua register dapat sekaligus diakses dalam satu instruksi yang dieksekusi tiap clocknya. Sehingga arsitektur seperti ini lebih efisien dalam eksekusi kode program dan dapat mencapai eksekusi sepuluh kali lebih cepat dibandingkan mikrokontroler CISC (Complete Instruction Set Computer) [1].
Karbon Monoksida adalah gas beracun, tidak berwarna, tidak berbau, dan tidak berasa. Karena sifatnya tersebut, CO biasanya tercampur dengan gas-gas lain yang berbau sehingga CO dapat terhirup secara tidak disadari bersamaan dengan terhirupnya gas lain yang berbau. CO dihasilkan dari limbah industri dan kendaraan bermotor terutama dari hasil pembakaran tidak sempurna gas alam dan material-material lain yang mengandung karbon. Karbon Monoksida merupakan salah satu polutan yang terdistribusi paling luas di udara. Setiap tahun, CO dilepaskan ke udara dalam jumlah paling banyak diantara polutan udara yang lain, kecuali $\mathrm{CO}_{2}$. Di daerah dengan populasi tinggi, rasio mixing $\mathrm{CO}$ bisa mencapai 1 hingga 10 ppmv [2].

Sensor gas TGS 2600 digunakan untuk mendeteksi udara yang terkontaminasi, fitur yang ditawarkan oleh sensor gas ini adalah selain tahan lama dan harga murah adalah menggunakan tegangan yang rendah (low power consumption), memiliki sensitivitas yang tinggi terhadap udara yang terkontaminasi, serta ukurannya yang kecil. Sensor ini termasuk dalam golongan sensor analog, hal ini berarti bahwa sensor gas figaro mempunyai nilai yang variatif. Sensor ini mempunyai nilai Rs yang akan berubah bila terkena gas dan juga mempunyai sebuah pemanas (heater) yang digunakan untuk membersihkan ruangan sensor dari kontaminasi udara luar [3].

Modem Wavecom M1206B adalah GSM/GPRS modem yang siap digunakan sebagai modem untuk suara, data, fax dan SMS. Kelas ini juga mendukung 10 tingkat kecepatan transfer data. Wavecom M1206B dengan mudah dikendalikan dengan menggunakan perintah AT. Dapat dengan cepat terhubung ke port serial usb komputer desktop atau notebook. casing logam 
Wavecom M1206B menjadi solusi yang tepat untuk aplikasi berat seperti telemetri atau Wireless Local Loop (PLN metering \& Telepon Umum). Ukurannya agak kecil memudahkan dalam peletakan di berbagai macam area, indoor/outdoor.

Cocok sekali digunakan pada aplikasi server pulsa yang menghendaki kemampuan optimal dan usia pakai panjang, software aktifasi kartu perdana, telemetri, SMS gateway/broadcast yang handal, PPOB PLN, ATM, Payment Point Systems, Metering Listrik. Dibangun dari platform chipset M1206B yang terkenal cepat dan irit konsumsi listrik, namun pada Wavecom M1206B ini seluruh komponen dibangun dari komponen berkualitas tinggi dan tahan lama. Penggunaan module Wavecom Wismo yang mendukung format Open-AT pada Wavecom mendasari kinerja optimal yang tidak mengurangi daya tahan modem itu sendiri. Terlebih module Wismo Open-AT yang disematkan memiliki original IMEI dan dilengkapi prosesor ARM yang cocok untuk device mobile seperti modem Wavecom M1206B. Bagi anda yang berbisnis server pulsa ataupun SMS broadcast,aktifasi kartu perdana massal, modem ini tidak salah lagi sangat cocok digunakan untuk menghemat pengeluaran retur/beli kembali setiap modem-modem yang dipakai, dengan realibilitas perangkat yang mumpuni dan stabil dengan dukungan koneksi USB pada baudrate: 115200 [4].

Gateway berarti pintu gerbang, sehingga dalam istilah ini, SMS Gateway berarti pintu gerbang/jembatan antara dua buah device atau lebih. Umumnya SMS Gateway ini berupa sebuah komputer yang didalamnya telah terinstall aplikasi untuk menangani pengiriman pesan antar handphone. Dalam hal ini, SMS gateway berfungsi sebagai aspek pusat yang menangani pengiriman surat sesuai dengan alamat yang dituju. SMS Gateway adalah sebuah aplikasi Short Message Service (SMS) yang dapat di jalankan melalui Local Area Network (LAN). Aplikasi ini dapat digunakan bersama-sama dalam satu jaringan. Walaupun aplikasi ini digunakan oleh beberapa user tapi hanya mempunyai satu module GSM/CDMA. Dimana bagian pemrosesan ini berfungsi melakukan operasi pemrosesan pesan yang diterima, meliputi proses pemecahan pesan (parsing), eksekusi proses yang dipilih user, akses database, dan menghasilkan respon hasil proses [5].

Untuk mendeteksi gas CO sensor terhubung ke ADC mikrokontroler di port A dengan tegangan 5 volt DC dengan range ADC 01023. Untuk pendeteksian gas CO ditetapkan bahwa nilai maksimal sensor untuk mendeteksi gas CO adalah sebesar 30 ppm. Dari ketetapan tersebut didapatkan fungsi keanggotaan gas CO untuk nilai fungsi keanggotaannya dengan range 0-30 ppm. Maka agar skala fungsi keanggotaannya sesuai yaitu 30 ppm maka nilai ADC harus dibagi dengan 34 yang dapat dicari dengan persamaan berikut :

$$
\text { Nilai Pembagi ADC }=\frac{\text { Nilai ADC }}{\text { Gas CO }(\mathrm{ppm})}
$$

Keterangan :

Nilai ADC : :1024

Gas CO (ppm) : Nilai Maksimum Gas CO (ppm).

\section{METODE PENELITIAN}

Tahapan yang dilakukan dalam penelitian ini yaitu dengan metode perencanaan dan perancangan. Sebagai langkah awal perencanaan adalah menentukan suatu sistem yang akan dibuat dan mengetahui prinsip kerjanya untuk memudahkan dalam proses pembuatan alat. 
Langkah selanjutnya adalah membuat suatu diagram blok dari sistem ini sendiri sehingga dapat menggambarkan proses-proses yang akan dikerjakan dalam perancangan alat. Dalam hal ini sistem yang akan dibuat adalah alat pendeteksi gas CO pada mobil berbasis SMS Gateway menggunakan array sensor.

\section{Perancangan Hardware}

Pada perancangan sistem ini akan dibahas tentang perancangan alat pendeteksi gas CO pada mobil berbasis SMS gateway menggunakan mikrokontroller ATMega 32, Berikut diagram bloknya seperti ditunjukkan pada gambar 1 .

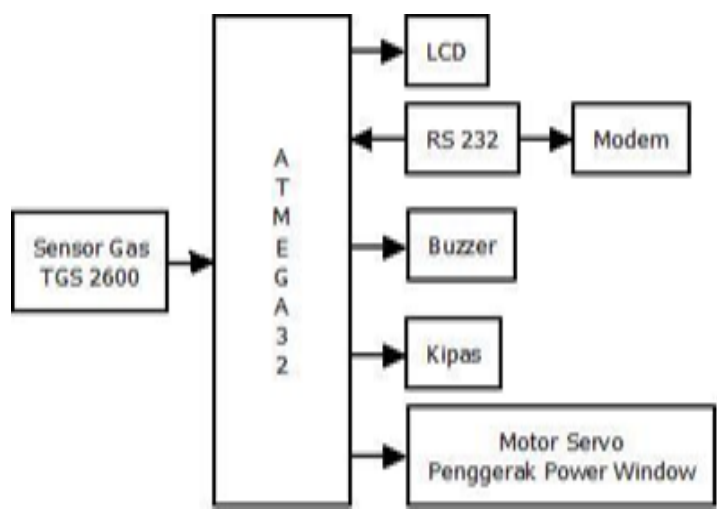

Gambar 1. Blok Diagram Alat Pendeteksi Gas CO menggunakan Array sensor dan berbasis SMS Gateway.

Gambar 2. berikut adalah rancangan Blok rangkaian elektronik keseluruhan alat pendeteksi gas beracun CO pada mobil berbasis sms gateway sebagai berikut :

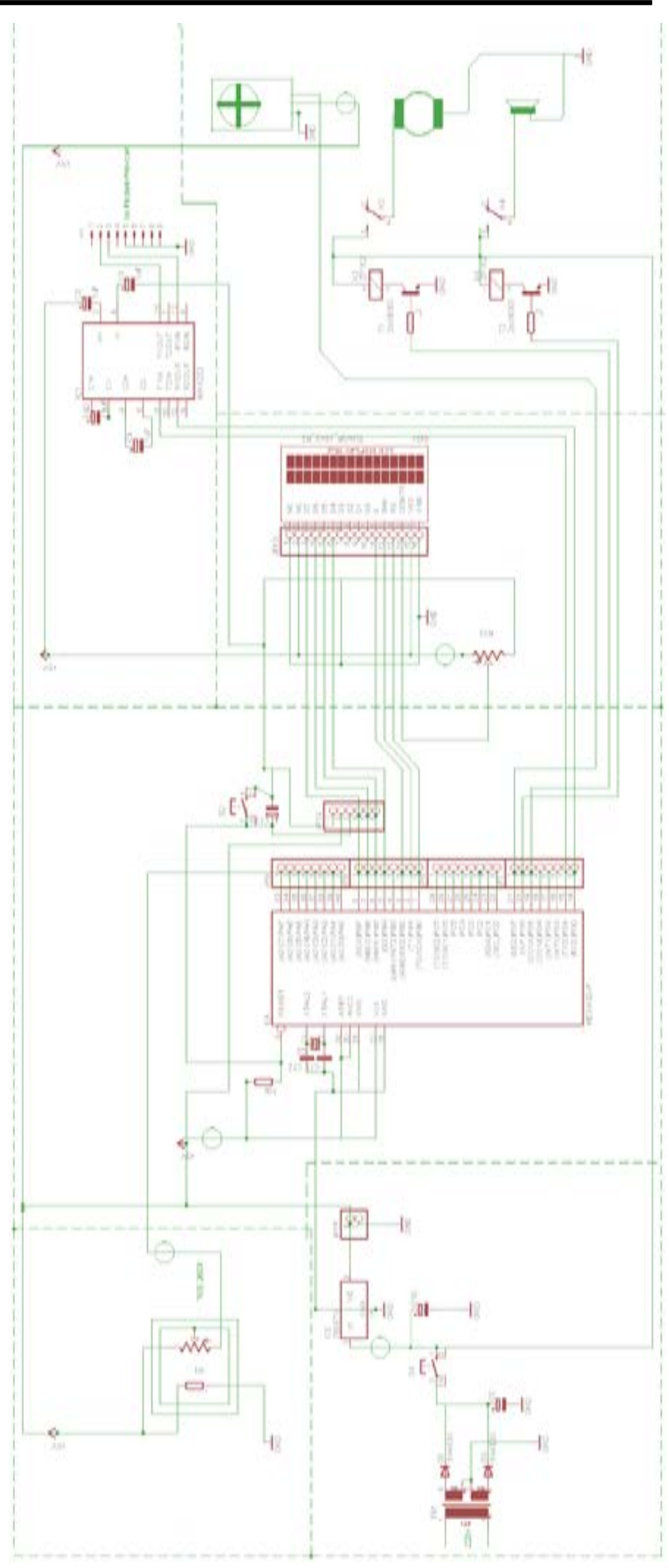

Gambar 2. Rancangan Rangkaian elektronik keseluruhan alat pendeteksi gas beracun CO (Carbon Monoxida)

Pada Gambar 2. menjelaskan blok diagram dari alat yang dirancang yang terdiri dari komponen kerja alat sebagai berikut: 
a. Sensor Gas Figaro TGS 2600

Merupakan komponen yang digunakan untuk mendeteksi kadar gas CO di dalam mobil, dan sebagai masukan data bagi mikrokontroler.

b. Mikrokontroler ATMega32

Merupakan komponen utama yang berfungsi sebagai pengolah data dan pengontrol keseluruhan system dan mengirimkan data ke buzzer dan motor servo serta modem dan LCD.

c. RS23

Alat komunikasi serial untukbmenghubungkan mikrokontroler dengan modem.

d. Modem

Untuk mengirimkan peringatan melalui sms gateway.

\section{e. Buzzer}

Merupakan komponen yang digunakan untuk memberikan tanda suara/bunyi seperti alarm.

\section{f. Motor Servo}

Sebagai penggerak power window otomatis ketika kondisi bahaya.

g. LCD

Merupakan komponen yang digunakan untuk menampilkan teks.

h. Kipas

Untuk menetralisir udara didalam mobil ketika terjadi kondisi bahaya.

\section{Prinsip Kerja Alat}

Alat pendeteksi kebocoran gas CO ini akan bekerja apabila udara disekitar alat ini mengandung gas yang berbahaya yaitu gas CO, jika gas tersebut telah terdeteksi maka sensor TGS akan memberi input ke mikrokontroler, kemudian mikrokontroler tersebut memiliki lima output yaitu LCD, Buzzer, Modem untuk mengirim SMS Gateway, Kipas untuk menetralisir udara, dan Motor Servo untuk menggerakkan Power Window secara otomatis.. Dengan menggunakan sensor
TGS 2600, apabila udara disekitar sensor tercemar maka sensor ini akan bekerja aktif untuk mendeteksi udara disekitarnya.. Apabila LCD menampilkan teks "Status Aman”, itu berarti kandungan gas CO didalam mobil tersebut dalam kondisi aman. Jika LCD menampilkan teks "Status Mendekati Bahaya”, itu berarti kandungan gas CO didalam mobil tersebut mulai mengalami peningkatan. Jika LCD menampilkan teks "Status Bahaya” dan buzzer menyala, itu berarti kadar gas CO didalam mobil berada pada kondisi warning atau mulai berbahaya. Namun, apabila LCD menampilkan teks "Status Sangat Bahaya" dan modem mengirimkan pesan "Bahaya", berarti udara didalam mobil tersebut telah mengandung gas CO yang sangat berbahaya karena telah melebihi ambang batas maksimal udara yang telah ditetapkan. Kemudian buzzer akan mengeluarkan suara yang diikuti oleh gerakan motor servo untuk menggerakkan power window yang terbuka secara otomatis lalu diikuti oleh putaran kipas yang berfungsi untuk menetralisir udara. Apabila udara didalam mobil tersebut secara perlahan mulai menetral, maka secara otomatis pula buzzer akan mati, lalu output lainnya akan menyesuaikan ke kondisi awal. Driver berfungsi sebagai penghubung tambahan untuk menghubungkan antara mikrokontroler dengan buzzer dan kipas. Penjelasan mengenai diagram alir alat pendeteksi gas CO pada mobil berbasis sms gateway dalam bentuk Gambar 3. berikut ini : 


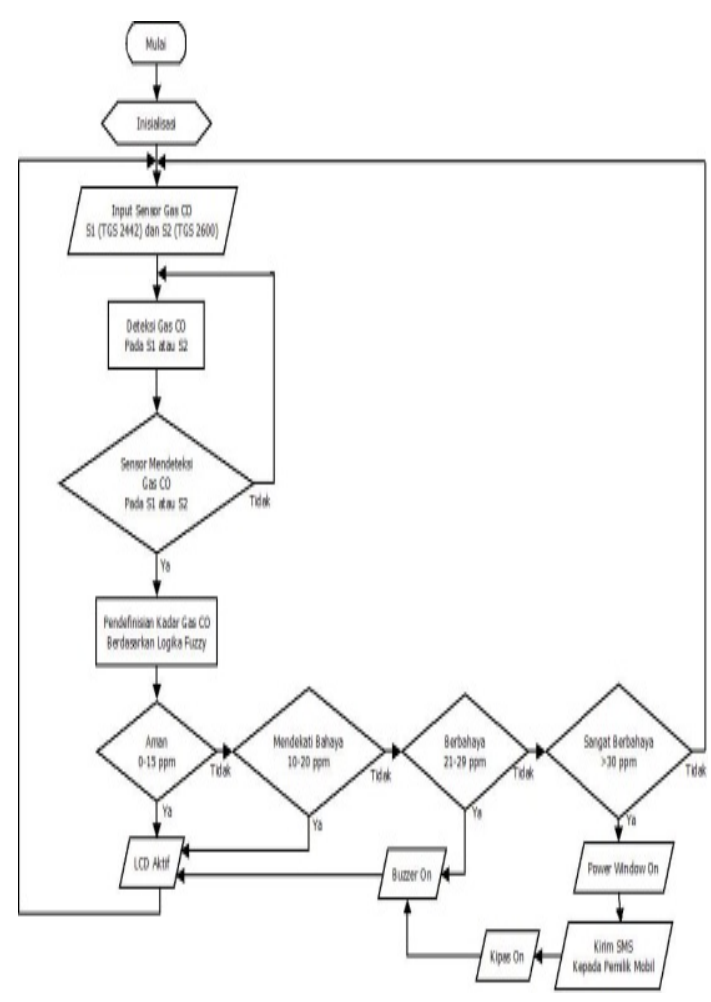

Gambar 3. Flowchart Sistem Alat Pendeteksi Gas CO

\section{Pengukuran dan Pengujian Alat}

Pada penelitian ini dilakukan pengukuran terhadap bagian-bagian dari rangkaian elektronik pada rangkaian alat pendeteksi gas CO yang terdiri dari rangkaian power supply, rangkaian antara mikrokontroler dan driver kipas, rangkaian antara mikrokontroler dan driver buzzer,pengukuran sensor Gas TGS 2600, pengukuran pada motor servo, dan pengukuran pada LCD dan prinsip kerja dari alat yang telah dibuat. Hal ini bertujuan untuk mengetahui bagian-bagian tersebut berfungsi dengan benar atau tidak. Pengujian dan pengukuran pada rangkaian elektronik dilakukan dengan memperhatikan titik-titik pengukuran (TP). Setelah pengujian dan pengukuran dilakukan maka didapatkan hasil analisa yang secara langsung merupakan spesifikasi dari alat yang telah dibuat.
Tabel 1. Hasil Pengukuran Pada Input Sensor TGS 2600

\begin{tabular}{|c|c|c|c|}
\hline $\begin{array}{c}\text { Pengu } \\
\text { jian } \\
\text { Ke- }\end{array}$ & Kondisi & $\begin{array}{c}\text { Tegangan Pada } \\
\text { Input Sensor TGS } \\
\mathbf{2 6 0 0}\end{array}$ & $\begin{array}{c}\text { Kadar } \\
\text { Gas } \\
\text { CO }\end{array}$ \\
\hline $\mathbf{1}$ & Aman & 0,3 VDC & $4 \mathrm{ppm}$ \\
\hline $\mathbf{2}$ & $\begin{array}{c}\text { Mendekati } \\
\text { Bahaya }\end{array}$ & 1,2 VDC & $\begin{array}{c}10 \\
\mathrm{ppm}\end{array}$ \\
\hline $\mathbf{3}$ & Bahaya & 3,2 VDC & 22 \\
& Spm \\
\hline $\mathbf{4}$ & $\begin{array}{c}\text { Sangat } \\
\text { Bahaya }\end{array}$ & 4 VDC & $\begin{array}{c}26 \\
\mathrm{ppm}\end{array}$ \\
\hline
\end{tabular}

Dari tabel 1. diatas dapat dilihat bahwa berdasarkan ketentuan yang telah dibuat dalam sistem rangkaian guna mengontrol kadar gas CO didalam mobil yang tertutup terlihat bahwa semakin besar kadar gas yang terdeteksi oleh sensor maka semakin besar pula tegangan yang dihasilkan oleh masing-masing sensor. Ketika kadar gas CO terdeteksi oleh sensor maka alat ini akan mengidentifikasi gas CO berupa sinyal analog. Sinyal analog ini akan diolah dan dibandingkan dengan data yang diperoleh sebelumnya oleh mikrokontroler ATMega32. Data ini dikonversikan oleh mikrokontroler melalui ADC menjadi digital dan kemudian data tersebut ditampilkan oleh LCD berupa presentasi nilai dalam satuan ppm.

\section{HASIL DAN PEMBAHASAN}

Penelitian ini menghasilkan prototipe pendeteksi kebocoran Gas beracun CO pada gas buang kendaraan bermotor dengan ouput alarm,sms gateway, dan informasi kadar gas CO dalam kondisi aman, mendekati bahaya, bahaya dan sangat bahaya dalam tampilan LCD . Setelah dilakukan pengujian untuk mengukur kadar gas CO, maka akan tampil beberapa informasi yang ditampilkan pada rangkaian LCD (Liquid Circuit Display ) dijelaskan pada Gambar berikut ini : 


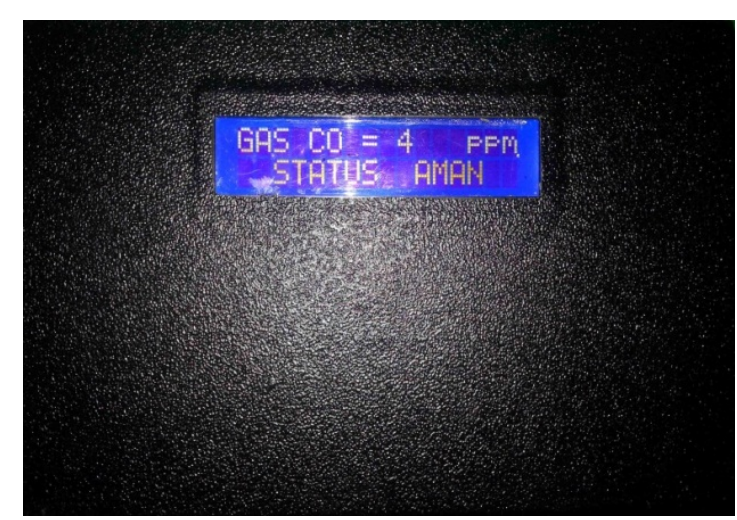

Gambar 4. Tampilan LCD Status Aman

Pada Gambar 5. adalah output LCD Status Mendekati Bahaya.

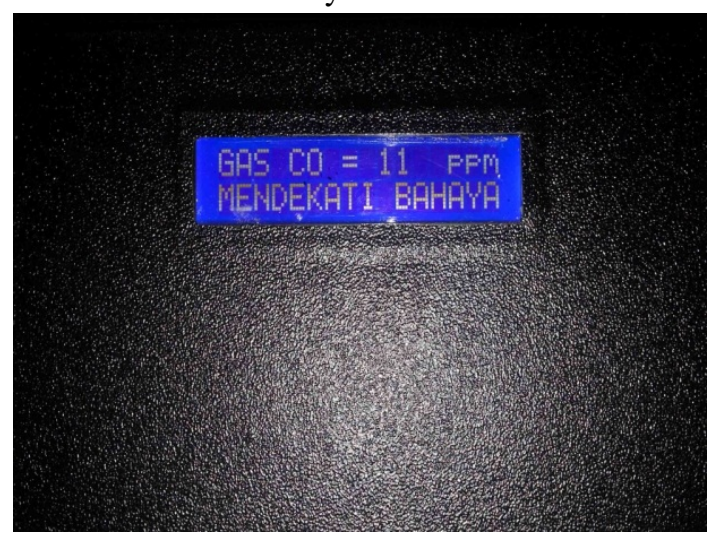

Gambar 5. Tampilan LCD Status Mendekati Bahaya

Pada Gambar 6. adalah output LCD Status Sangat Bahaya.

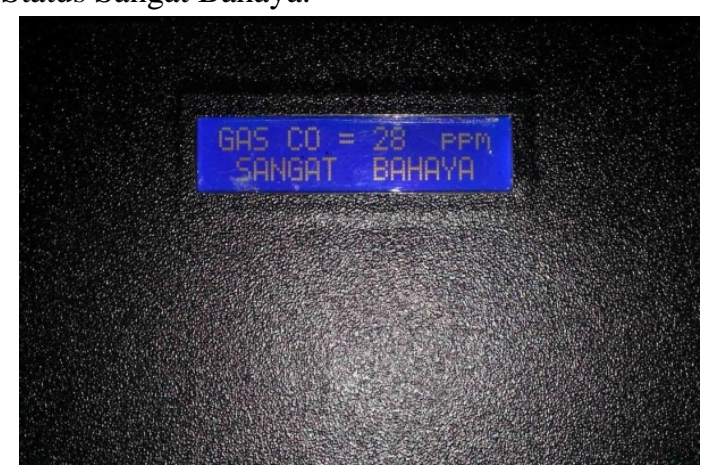

Gambar 6. Tampilan LCD Status Sangat Bahaya

Dalam proses pendeteksian gas ini, kerja mikrokontroler ATMega32 berlangsung sebagai berikut. Pada saaat PortA.1 mikrokontroler ATMega32 mendeteksi adanya polusi udara yang berasal dari gas maupun asap berbahaya maka mikrokontroler akan menjalankan proses pendeteksian gas CO.
Proses pendeteksian gas CO sebagai berikut, sensor akan memberikan data yang telah diprosesmya pada PortA.1 ke mikrokontroler. Kemudian data tersebut akan diproses oleh mikrokontroler sesuai dengan program yang ada. Data hasil proses tersebut akan langsung dikeluarkan oleh mikrokontroler ke beberapa outputnya. Pada PortD yaitu LCD akan menampilkan pesan kadar bahaya dan jumlah kadar gas CO dalam ppm. Untuk rangkaian buzzer dan kipas hanya akan berlogika 1 apabila kadar gas telah melewati batas yang telah dibuat dalam system domain fuzzy. Rangkaian ini terhubung ke PortC.0 dan PortC.1. Motor servo akan membuka sesuai dengan kadar gas CO yang terdeteksi. Motor servo terhubung ke PortD.7. Modem aktif jika kadar gas CO telah sangat berbahaya. Modem terhubung ke Port.D.0 dan PortD.1.

\section{KESIMPULAN}

Simpulan dari penelitian yang sudah dilakukan, berdasarkan hasil perancangan dan hasil pengujian yang telah dilakukan pada Alat Pendeteksi Kebocoran Gas CO Pada Mobil Berbasis SMS Gateway Menggunakan Array sensor yaitu :

1. Kenaikan Vout yang terjadi pada input sensor dipengaruhi oleh tingkat kontaminasi keadaan udara disekitar pendeteksian sensor.

2. Skala yang didapatkan sebagai perbandingan data maksimun tingkat pendeteksian dengan kadar deteksi akhir sensor 30 ppm berada pada level tegangan 4,24 VDC dan nilai terendah deteksi sensor dengan 1 ppm berada pada level tegangan 0,09 VDC. 


\section{REFERENSI}

[1] Winoto, Ardi. 2010. Mikrokontroler AVR ATMega8/32/16/8535 dan Pemrogramannya dengan Bahasa C pada WinAVR. Yogyakarta: Andi.

[2] http://www.dirgantara-lapan.or.id, Diakses 15 Mei 2013.

[3] www.deltaelectronik.com/sensorgasfigaroT S2600, Diakses 17 Mei 2013
[4] Rahma Sari, Eka. 2012. “Alat Pendeteksi Kebocoran Gas Beracun CO Pada Mobil Menggunakan Array Sensor Dengan Fuzzy Controller”. Teknik Komputer. Politeknik Negeri Sriwijaya. Palembang.

[5] Kusumadewi, Sri \& Hari Purnomo. 2010. Aplikasi Logika Fuzzy Untuk Pendukung Keputusan. Yogyakarta: Graha Ilmu 